\title{
Verticatidade é sinônimo de boa postura?
}

\author{
Adriane Vieira* \\ Jorge Luiz de Souza**
}

A avaliação da postura corporal através da posição ortostática tem sido utilizada há várias décadas e por muitos autores como um instrumento para verificar se a pessoa apresenta postura normal ou, em outras palavras, boa postura. Nessa avaliação, o alinhamento e a simetria dos segmentos corporais são os, parâmetros utilizados para a definição da boa postura, isto é, pressupõe-se que a verticalidade corporal e a simetria representam o bom equilíbrio muscular e o bom funcionamento dos sistemas ósteo-articular e muscular. Mas o que significa ter boa postura? Será que podemos afirmar que a verticalidade na posição ortostática é sinônimo de boa postura? Será que a pessoa que apresenta um bom alinhamento dos segmentos corporais não sofre de problemas álgicos e articulares? Propomos, a partir dessas questões, discutir os pressupostos e a validade da avaliação da posição ortostática para classificar a qualidade da postura corporal.

\section{Verticalidade e Boa Postura}

O alinhamento dos segmentos corporais é considerado um parâmetro de boa postura desde Cícero (143-103 a.C.) e Santo Ambrósio (340-397 d.C.). Nessa época, os desvios dos segmentos corporais, o relaxamento muscular e a peida da compostura eram vi-stos como sinais de desvirtuamento da alma, sendo valorizada a capacidade de restringir gestos e posturas por indicarem virtudes morais. Acreditava-se que uma disciplina corporal, apoiada em valores da razão humana ou do olhar de Deus, poderia influir sobre a alma para conformá-la às normas morais. Na Idade Média," o posicionamento mediano do corpo e o alinhamento da cabeça ainda tinham conotação moral, sendo a modéstia - entendida como o ideal da medida e o justo meio - a virtude específica do gesto e da postura' (Schmitt, 1995).

No século XVII, quando as descobertas da Física revolucionaram o pensamento ocidental e se firmou a analogia entre corpo e máquina, a retitude corporal continuou a ser considerada requisito à boa postura, mas como uma qualidade mecâncicado corpo e não mais como uma virtude
Moral. Os desvios dos segmentos corporais passaram a ser entendidos c o m o proble ma s musculares e ósteoarticulares, que deveriam ser tratados através de uma intervenção mecânica. Para garantir a boa postura, os especialistas passaram a recomendar a utilização de panóplias corretivas, (aparelhos metálicos ou espartilhos), embasadas nas leis mecânicas da Física, inicialmente como uma medida terapêutica e, posteriormente, como uma medida preventiva de problemas posturais (Vigarello, 1995). No século XIX, essas ações externas foram trocadas por ações internas de contrações musculares corretivas através de exercícios para reforço muscular. Utilizàvase aparelhos contra os quais se deveria aplicar forças previamente medidas, orientadas e contabilizadas. Mas, para Vigarello (1 995), as panóplias corretivas e as contrações musculares corretivas, muito mais que medidas mecânicas e estéticas, como eram consideradas, continuavam a ser um recurso pedagógico à disciplina corporal.

A postura militar, reconhecida, por muito tempo, como protótipo de boa postura, tam- 
bem se embasava numa disciplina corporal rigorosa, da qual fazia parte o bom alinhamento dos segmentos corporais. Os soldados eram, até o século X VII, selecionados pelas suas aptidões físicas, pelo seu porte e postura; mas, a partir do século XVIII, a fisionomia de soldado passou a ser desenvolvida nos recrutas por meio de ações pos-turais corretivas, fazendo-se "de uma massa informe, de um corpo inapto, $[. .$.$] a máquina$ de que se precisava" (Foucault, 1996, p. 125). A postura era, então, treinada para apresentar, segundo Foucault (1996) as seguintes características: cabeça alta e ereta, costas retas, ventre encolhido e peito saliente. Tambérri fazia parte dessa disciplina corporal "nunca fixar os olhos na terra, [...Jolhar com ousadia aqueles diante de quem eles passam, [...] ficar imóveis esperando o comando" (Foucault, 1996, -p. 125).

O conforto e o bem-estar c orpora 1 ñ̃ o s̃ o mencionados em nenhum desses momentos históricos, e o cuidado com a postura parecia muito mais direcionado ao controle do corpo para moldá-1o a padrões morais, estéticos e culturais do que ao bom funcionamento do organismo. Será que, passado um século, mudaram as concepções sobre a postura corporal?

A revisão bibliográfica de alguns livros publicados na segunda metade desse século demostrou que as leis mecânicas da Física corpo humano área de estudo denominada Biome-cânica ainda são utilizadas no estudo da postura corporal (Kelly, 1949; Anderson, 1951 ; Metheny, 1952; Bo-wen, 1953; Rasch \& Burke, 1977; Kendall, McCreary \& Provance, 1995; Knoplich, 1996; Smith, Weiss \& Lehmkuhl, 1997). Os autores normalmente definem a postura como as posições ou atitudes que o coipo assume nas situações cotidianas (subir e descer escadas, deitar, sentar, ficar em pé e caminhar) e concordam que as forças internas e externas que agem no corpo influenciam a postura, mas discordam ao definir os parâmetros que caracterizam a boa postura.

Dentre os autores que defen4em o bom alinhamento dos àegmentos corporais na posição ortostática como requisito à boa postura, podemos destacar Kendall, McCreary \& Provance (1995), considerados uma das principais referências bibliográficas ao estudo da postura corporal. Eles afirmam que a postura ideal ou padrão é representada pela retitude dos segmentos corporais na posição em pé e estática. Na postura-pa-drão:

\footnotetext{
"a coluna apresenta as curvaturas normais e os ossos dos membros inferiores ficam em alinhamento ideal para sustentação de peso. A posição 'neutra' da pélvis conduz ao bom alinhamento do abdómen, do tronco e dos membros inferiores. O tórax e coluna superior ficam em uma posição que favorece a
}

função ideal dos órgãos respiratórios. A cabeça fica ereta em uma posição bem equilibrada que minimiza a sobrecarga sobre a musculatura cervical." (Kendall, McCreary \& Provance, 1995, P-71)

Para averiguação do alinhamento postural, esses autores sugerem uma avaliação através do teste do fio de prumo $^{2}$, no qual se observa o posicionamento de pontos de referencia anatómica $^{3}$ em relação à linha do fio de prumo. Quando os pontos de referência da pessoa que está sendo avaliada passam sobre a linha do fio de prumo, análoga à linha da gravidade, os autores afirmam que há uma distribuição equilibrada do peso, uma posição estável de cada articulação e uma atividade muscular mínima, ou seja, que a pessoa apresenta boa postura. Por outro lado, quando esses pontos de referência afastamse da linha do fio de prumo, eles "revelam a extensão na qual o alinhamento dessa pessoa é defeituoso" (Kendall, McCreary \& Provance, 1995, p.71) e indicam os encurtamentos e as fraquezas musculares que o indivíduo apresenta. É importante destacar, no entanto, o que afirmam os autores na mesma página: "Não se espera que alguém consiga combinar o padrão em cada aspecto, nem os autores jamais viram alguém que o fizesse."(Kendali, McCreary \& Provance, 1995 , p.71)

Smith, Weiss \& Lehmkuhl (1997), dentre outros, discordam dos supracitad o s e d i z e m 
que o teste do fio de prumo não serve para avaliar a boa postura. Para eles, a postura idealmente vertical não é natural, sendo necessário solicitá-la, o que determina esforço consciente e aumento acentuado da atividade muscular. Defendem, assim, que o parâmetro de uma postura ereta normal deve ser o relaxamento e o conforto corporal, em vez de um modelo ideal e prédeterminado de alinhamento corporal. Os autores sugerem que a postura-padrão com base em pontos de referência anatómica surgiu de um engano na leitura do artigo de Braune e Fischer publicado em 1889, no qual são definidos pontos de referência anatómica para plotar o corpo e não para determinar parâmetros à postura normal.

Metheny (1952), no livro Body Dinamics, também afirma que:

\begin{abstract}
"'Não existe uma só postura melhor para todos os indivíduos. Cada pessoa deve pegar o corpo que tem e tirar o melhor proveito dele. Para cada pessoa, a melhor postura é aquela em que os segmentos corporais estão equilibrados na posição de menor esforço e máxima sustentação. Essa é uma questão individual" (p. 193).
\end{abstract}

Esses autores concordam que a boa postura caracterizase por uma atividade muscular mínima; mas enquanto os primeiros argumentam que a postura-padrão seria a de menor utilização muscular, os últimos dizem que a posturapadrão, por não ser uma ati-
Tude natural, exige um aumento considerável da atividade muscular. Como medir a quantidade de esforço muscular que a pessoa utiliza para a s u m ir u m a determinada postura? Será que os esforços musculares podem ser identificados através do posicionamento dos segmentos corporais? Como avaliar o conforto e o relaxamento musculares? As divergências teóricas presentes entre autores de uma mesma perspectiva indicam o quanto é difícil determinar a postura que solicita menor esforço muscular, fa-tor por e 1 e s c o n s i d e r a d o preponderante para definição d a b o a p s t u r a .

Considerando que a estrutura corporal está sujeita à força da gravidade, podemos afirmar que quanto mais desalinhados estiverem os segmentos corporais, maior será a força muscular necessária para equilibrá-los uns em relação a outros e todos em relação à base de sustentação. Contudo, se para obter o alinhamento corporal tivermos de realizar contraçoes musculares voluntárias e mante-las constantemente, deparamonos com o mesmo problema: o a umento de tensão muscular..Muitos dos desenhos, fotografias e descrições de boa postura (ver páginas 6-7) presentes nos livros que defendem o bom alinhamento corporal no fio de prumo (Kelly, 1949; Bowen, 1953; Kendall, McCreary \& Provance, 1995; Knoplich, 1996) são, em geral, bastante semelhantes à fisionomia de $s$ o $l d a d o \mathrm{~d}$ e s c r i t a anteriormente, a qual em nada condizem com uma postura confortável, mas com certa rigidez e tensão muscular. Poderíamos então questionar se é a ideia de verticalidade que é inadequada, ou se é a maneira de entender o que é uma boa verticalidade que está equivocada. Alguns autores, como Rasch \& Burke (1977), relacionam tensão e força muscular com boa postura, considerando a fraqueza muscular uma das principais causas da má postura. Eles sugerem que:

\footnotetext{
"os ossos, os tendões e os mús culos devem ser fortalecidos e endurecidos através de esforços e resistência, gradualmente progressivos, de modo que elas pos a c confrontar, adequadamente, com as forças comuns encontradas na vida coíidiana." (p. 439)
}

No livro Viva Bem com a Coluna que Você Tem, Knopiich (1996) relaciona boa postura e tensão muscular ao falar sobre a maneira correta de caminhar:

"O método cprreto de andar é
olhando sempre para a linha do
horizonte, olhando as pessoas
nos olhos e até mesmo com um
certo ar de arrogância. Isso
significa que a cabeça está
erguida e não apenas os
ombros. O caminhar de cabeça
baixa dá um certe ar de timidez,
insegurança. Ao caminhar,
contraia a musculatura
abdominal e as nádegas."
(p.139)

Será que músculos endurecidos e contraçoes musculares voluntárias podem contribuir à aquisição de boa postura? Por exem $\mathrm{p} 1 \mathrm{o}, \quad \mathrm{c}$ o $\mathrm{m} \mathrm{o} \quad \mathrm{s} \mathrm{e}-$ 
ria possível, durante o caminhar, realizar a flexão da articulação coxo-femural se as nádegas, responsáveis pela extensão dessa articulação, ficarem permanentemente contraídas? Para que serve erguer os ombros? Qual o benefício dessas contrações? Será que a contração ininterrupta e voluntária das nádegas, do abdômen-e dos ombros e o endurecimento muscular não levam os músculos à fadiga e as articulações à sofrerem sobrecarga?

Essas questões nos levam a inferir que, apesar dos autores citarem a tensão muscular como um fator prejudicial à postura, muitos ainda propõem um posicionamento adequado do corpo através do endurecimento muscular e do comando voluntário e exacerbado de contrações musculares, retratando, assim, certa incoerência teórica. Como será que os profissionais lidam com essas questões ao utilizar a posição ortostática como um instrumento para a avaliação da postura? O que propor para melhorar a postura classificada como defeituosa? Pode-se devolver o equilíbrio muscular alongando músculos encurtados e fortalecendo músculos fracos, tal como sugerido pela maioria dos autores citados? Será que a boa postura pode ser avaliada pela simples observação da posição ortostática?

Finalizando essa discussão, consideramos relevante ressaltar que termos como correção, defeito, ideal, bom, certo, errado, utilizados pela maioria dos autores que se referem à postura corporal, remetem a uma visão de postura vinculada à disciplina corporal. As considerações feitas por Knoplich( 1996) em relação à maneira correta de caminhar também sugerem que a literatura ainda enfatiza concepções morais na definição da boa postura. Sousa (1972) oferece outro exemplo bastante claro ao dizer que o indivíduo com boa postura "verá a vida de um ponto de vista oti-mista, ganhará o respeito de seus concidadãos e será um membro útil à sociedade" (p.50). Poucos dos autores consultados, como Rasch \& Burke (1977), salientam a interferência de padrões estéticos ou sociais no que a literatura define como uma postura biomecanicamente adequada. Podemos, então, questionar se realmente a valorização da verticalidade como preceito à boa postura está emba-sada apenas em parâmetros biomecânicos, ou se conceitos morais, estéticos e culturais estão camuflados no discurso biomecânico. Segundo o antropólogo Mauss (1974), desde cedo somos ensinados ou aprendemos pela observação e convivência com adultos a gesticular, movimentar e posicionar-nos conforme os padrões culturais ${ }^{4}$; por isso, considera que "talvez não exista 'maneira natural' no adulto" (Mauss, 1974, p. 216). Os valores sócio-cultu-rais são insculpidos no corpo através do que Mauss (1974) denominou técnicas corporais e, provavelmente, inter- ferem na maneira de concebermos e corrigirmos problemas.posturais. No livro Les Corps Redressé, Vigarello (1978) diz que:

\begin{abstract}
"O corpo é o primeiro lugar. onde a mão do adulto marca a criança, é o primeiro espaço onde se impõem os limites sociais e psicológicos dados à sua conduta, c o emblema onde, tal como nos brasões, a cultura inscreve seus signos", (p.9).
\end{abstract}

Essas colocações nos fazem questionar de é válido desconsiderar a influência dos valores socioculturais no pensar, sentir e agir tanto do indivíduo quanto do próprio especialista $^{5}$. A concepção do que é adequado ao organismo em termos posturais pode estar distorcida por valores estéticos, morais e culturais que só serão identificados se autores, professores e alunos discutirem sobre o assunto.

ConsideraÇÕEs finais

Pensamos que a postura é uma maneira de a pessoa pensar, agi? e sentir através de sua estrutura corporal, ou seja, a maneira pela qual a pessoa se expressa corporalmente no mundo. Os hábitos posturais e gestuais de cada pessoa estão relacionados: [1] à forma de seus ossos, músculos e articulações, que determinam padrões básicos de movimento e constituem o substrato de sua motilidade; [2] à sua imagem corporal, a qual vai configurando-se continuamente através da observação, da aprendizagem e dos valores socio culturais por ela inter- 
nalizados nas vivências; [3] através das suas percepções táteis, cinestésicas, visuais e auditivas, que a guiam no meio circundante.

Assim, definir boa postura para que possamos, através de uma avaliação, identificar possíveis problemas é uma questão bastante difícil e delicada. Conforme comentamos acima, os valores socioculturais e mora is estão tão internalizados na maneira de pensarmos, há tantas controvérsias teóricas a respeito do assunto e tantas diferenças entre uma pessoa e outra, que o normal se torna relativo. Entretanto, não podemos negar que a existência de problemas ósteo-articulares e musculares, tais como processos degenerativos e dores, pode dificultar o bemestar e interferir na qualidade de vida. Para propormos uma melhora da postura como uma das possibilidades à resolução desses problemas, temos de determinar o que é normal, ou seja, quais as características que podem preservar ou favorecer os sistemas ósteoarticular e muscular.

Dentro das limitações já citadas, definimos a postura normal como sendo a capacidade de manter e movimentar todas as partes do corpo de maneira coordenada e confortável, sem perder a m o b i lid a d e, s e m sobrecarregar a estrutura anatómica do indivíduo e sem gerar tensões desnecessárias nas mais variadas situações de vida diária, e, segundo colocou Metheny (1952), essas questões são peculiares a cada indivíduo, não há como determinar um padrão postural. Em relação à avaliação da posição ortostática, pensamos que-ela é um dado a ser considerado na avaliação dos aspectos que podem estar desencadeando dores e degenerações músculoarticulares, mas não é suficiente para caracterizar a qualidade da postura.

No nosso entender, a verticalidade não é sinónimo de boa postura; as "dores e degenerações músculoarticulares podem ser causadas tanto pelo alinhamento quanto pelo desalinhamento dos segmentos corporais, pois, nas duas situações, podem estar agindo forças indevidas que traumatizam os tecidos musculares e articulares.

Propomos, portanto, uma avaliação postural que considere todos aspectos envolvidos .na definição de postura corporal. E, de acordo com nossa definição, mesmo que o enfoque esteja d i r e c i o n a d o a questões ${ }^{v}$ musculares e articulares, a postura não pode ser desconectada do sujeito que a vive, ou, em outras palavras, que é essa postura. Concordamos, portanto, com autores que, compreendendo a limitação das avaliações que se çmbasàm principalmente na posição ortostática e no comprimento muscular, têm sugerido uma avaliação postural que considere as tensões musculares presentes em diversos hábitos posturais e as percepções que o indivíduo tem de seu próprio corpo (Lapierre;

1982; Bertherat, 1986; Ale- xander, 1992; Denys-Struyf, 1995; Souza, 1995; Vieira, 1998). A postura não é apenas uma questão de músculos fortes ou fracos e nem de uma posição específica; ela representa a dinâmica corporal assumida pelo indivíduo no seu dia-a-dia, estando vinculada a determinadas motivações que o levam a posicionar-se desta e não daquela maneira, à ideia que ele tem de sua postura e à maneira de ele perceber sua postura.

Referências bibliográficas

ALEXANDER, F. M. O uso de si mesmo. São Paulo: Martins Fontes, Í992.

ANDERSON, T. M. C. Hitmam kinetics and analysing body movemenls. London: William Heinemann Medicai Books, 1951.

BERTHERAT, T. O corpo tem suas razões: antiginástica $e$ consciência de si. 10.ed. São Paulo: Martins Fontes, 1986.

BOWEN, W. P. Applied anatomy and kinesiology: the mechanism of muscular movement. 7.ed. Philadelphia: Lea \& Febiger, 1953.

COOPER, J. M.; GLASSOW, R. B. Kinesiology. 3.ed. Saint Louis: The C. V. Mosby Company, 1972.

DENYS-STRUYF, G. Cadeias musculares e articulares: o método G.D.S. São Paulo: Summus, 1995.

FOUCAULT, M. Vigiar e punir: história da violência nas prisões, 14.ed. Petrópoíis: Vozes, 1987.

FREIRE, L. Grande e novíssimo dicionário da Língua Portuguesa. 3.ed. Rio de Janeiro: José Olympio, 1957. 
GONÇALVES, M. A. S. Sentir; pensar, agir: corporeidade e educação. Campinas: Papirus, 1994.

KELLY, E. D. Teaching posture and body mechanics. New York: Barnes and Company. 1949.

KENDALL, F. P., McCREARY, E. K.; PROVANCE, P. G. Músculos: provas e funções. 4.ed. São Paulo: Manole, 1995.

KNOPLICH, J. Viva bem com a coluna que você tem. 25.ed. São Paulo: Ibrasa, 1996.

LAPIERRE, A. A reeducação física. 6.ed. São Paulo: Manole, 1982. v.1.

MAUS S, M. Técnicas corporais. In: Sociologia e Antropologia. São Paulo: Editora da Universidade de São Paulo, p. 211233,1974 .

METHENY, E. Body dinamics. New York: McGraw-Hill, 1952.

RASCH, P. J.; BURKE, R. K. Cinesiologia e anatonia aplicada: a ciência do movimento humano. 5.ed. Guanabara Koogan: Rio de Janeiro, 1977.

SCHIMITT, J. C. A moral dos gestos. In: SANTANNA, D. B. (Org.). Políticas do corpo. São Paulo: Estação Liberdade, 1995.p.21-38

SMITH, L. K.; WEISS, E. L.; L E H M K U H L, L. D . Cinesiologia clínica de Brunns-trom. 5.ed. São Paulo: Manole, 1997.

SOUSA, A. V. Gimnasiá Correctiva. 2.ed. Barcelona: Sintes, 1972

SOUZA, J. L. Untersuchungen ziir Wirksamkeit von Bewegungsprogrammen bei Rückenbeschwerden. Inauguraldissertation zur Erlangung des Doktorgrades an der Fakultät fur Sozial und Verhaltenswissenschaften der Ruprecht-Karls-Universität Heidelberg, 1995.

VIEIRA, A. A corporeidade na Escola Postural. Dissertação de Mestrado. Universidade Federal do Rio Grande do Sul, 1998.

VIGARELlO, G. Panóplias Corretivas. In: SANTANNA, D. B. (Org.). Políticas do corpo. São Paulo: Estação Liberdade, 1995. p.21-38.

. Lê corps redressé:histoire d'un pouvoir pédagogique. Paris: Jean-Pierre Delarge, 1978.

Notas

"'Conserva-te firme a ti mesmo. Não te lances para baixo, não te eleves para o alto (...) Mantém o meio, se não queres perder a medida. $\mathrm{O}$ lugar médio é seguro. O meio é a sede da medida, e a medida é a sede da virtude" (São Bernardo apud Schmití, 1995, p.150).

" (. . .) não ba i x a n do humildemente a cabeça, dava a seu rosto uma aparência alongada: a nuca aprumada, ela fixava os olhos nas realidades superiores" (Alain de Lilleapwí/Schmitt, 1995,p.154)

"(...) ela delimita o gesto da cabeça, equilibra com justeza o rosto que ergue suavemente (...) Um rosto excessivamente abaixado para a terra indica um espírito ocioso e vazio (...) Quando o rosto não ultrapassa a medida, nem se elevando nem se abaixando, é qua a constância imprimiu sua marca ao espírito." (Alain de Lille apud Schmitt, 1995, p. 155)

${ }^{2} \mathrm{O}$ teste do fio de prumo é uma avaliação da posição ortostática através de uma íinha vertical. O teste consiste em verificar se os pontos de referência anatómica, correspondentes a postura-padrão no plano sagital e frontal, coincidem com o fio de prumo (Kendall, McCreary \& Provance, 1995).

${ }^{3}$ Os pontos de referência anatómica estão descritos no livro Provas e Funções Musculares de

Kendall, McCreary \& Provance (1995).

${ }^{4}$ Mauss (1974) sugere que todos os nossos hábitos são, em certa medida, vinculados a padrões e valores socioculturais, dando como exemplo o caminhar da tribo Maori (Nova Zelândia) documentada por Elsdon Best. Nessa tribo, o balançar destacado do quadril, chamado de "onioi", é ensinado e cobrado das filhas peias mães, sendo uma maneira adquirida e não natural de.caminhar.

" desenvolve a respeito de sua corporeidade è as suas formas de comportar-se corporalmente estão ligadas a condicionamentos sociais e culturais. [...] O corpo de cada indivíduo de um grupo cultural revela, assim, não somente sua singularidade pessoal, mas também tudo aquilo que caracteriza esse grupo como unidade." (Gonçalves, 1994, p. 13)

*Adriane Vieira é mestre em Ciências do Desenvolvimento Hum ano/ESEF/UFRGS. Professora do Curso de Fisioterapia da ULBRA e Faculdades Integradas do IPA. 

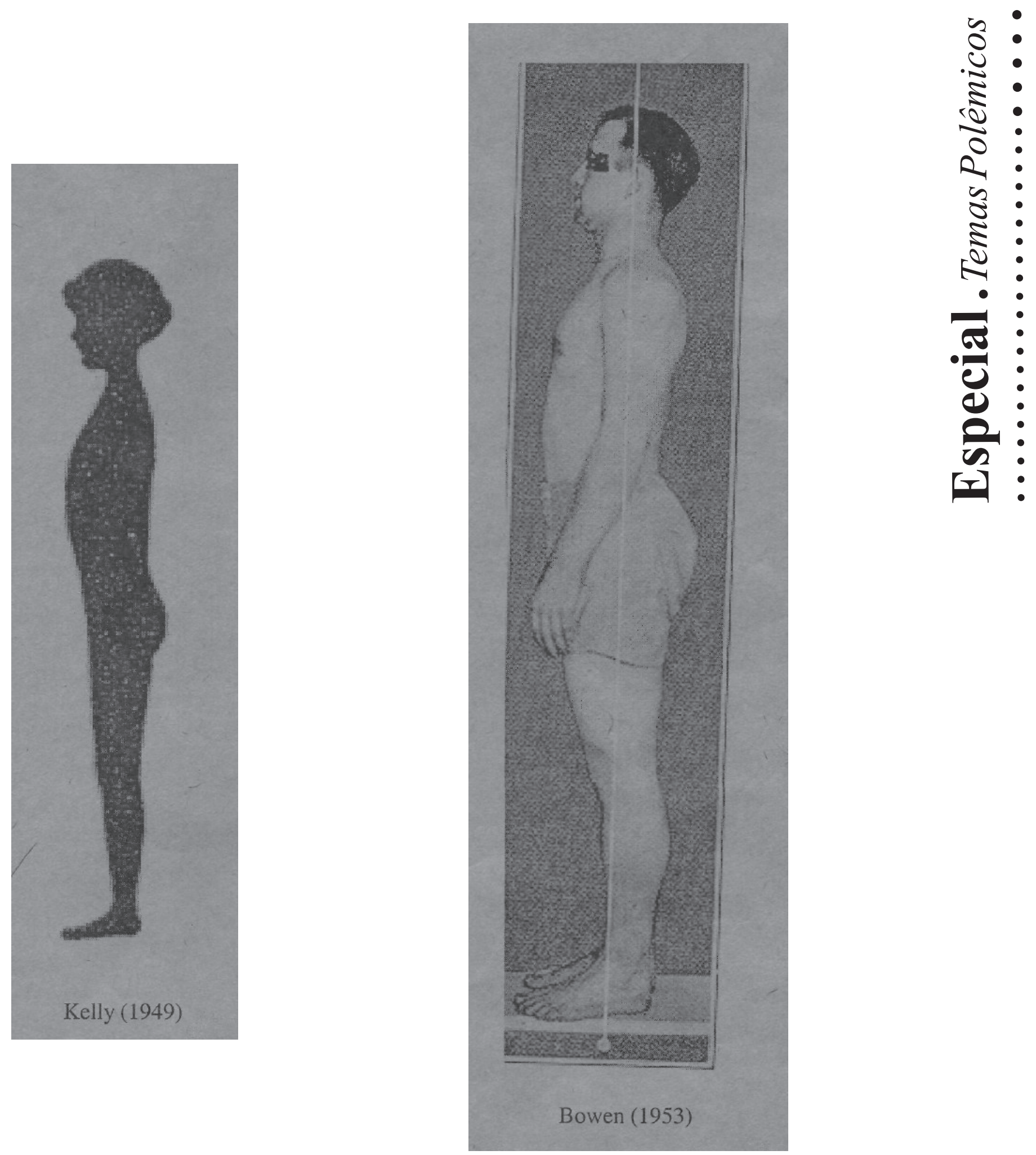
Movimento - Anov - No $10-1999 / 1$

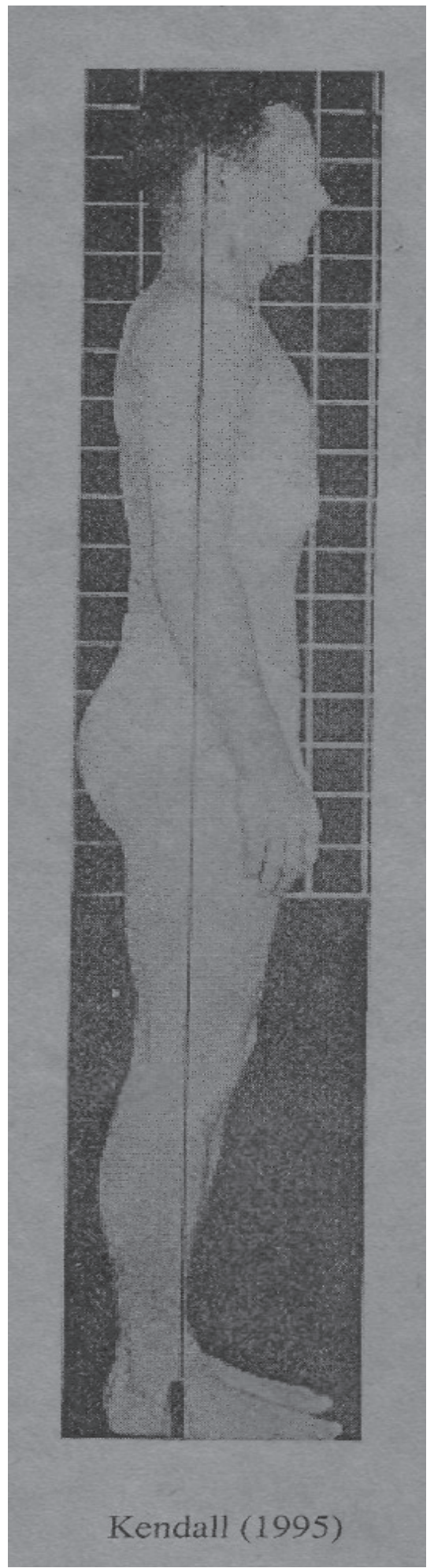

